|| ISSN(online): 2589-8698 || ISSN(print): 2589-868X ||

International Journal of Medical and Biomedical Studies

Available Online at www.ijmbs.info

NLM (National Library of Medicine ID: 101738825)

Index Copernicus Value 2019: 79.34

Original Research Article

Volume 5, Issue 11; November: 2021; Page No. 104-105

\title{
ROLE OF USG IN PATIENTS WITH ACUTE ABDOMEN
}

${ }^{1}$ Dr. Raghav Kumar, ${ }^{2}$ Dr. Saroj Kumari

${ }^{1,2}$ Assistant Professor, Department of Radiodiagnosis, SMS Medical College \& Associate Group of Hospitals, Jaipur

Article Info: Received 10 October 2021; Accepted 21 November 2021

DOI: https://doi.org/10.32553/ijmbs.v5i11.2308

Corresponding author: Dr. Saroj Kumari

Conflict of interest: No conflict of interest.

\section{Abstract}

Background: The main goal of imaging in acute abdomen is to narrow down the differential diagnosis and for prompt treatment.

Material and methods: This study was done on patient presented with acute abdomen in Department of Radiodiagnosis, SMS Medical College \& Associate Group of Hospitals, Jaipur. Scout X-ray done in 100 patients. Scout X -Ray film gives lots of information and very helpful in diagnosing perforation and intestinal obstruction.

Results: USG was able to diagnose $94 \%$ cases of perforation peritonitis. intestinal obstruction was diagnosed only in $73.17 \%$ of cases with USG.

Conclusion: This study shows that simple X-Ray plays an important role in definite diagnosis of acute abdomen as compare to USG.

Keywords: Ultrasound, X- Ray, Acute Abdomen

\section{Introduction}

The term acute abdomen defines a clinical syndrome characterized by abdominal pain of sudden onset developed over a period several hours requiring surgical or medical treatment ${ }^{1}$. Acute abdomen comprises $5-10 \%$ of people presenting as a general surgical emergency ${ }^{2}$. An early and accurate diagnosis is essential for prompt and appropriate management in order to limit morbidity and mortality. Moreover identification of surgical problems is utmost importance, as most patients of acute abdomen do not require surgery. A thorough history followed by meticulous clinical examination is no doubt cornerstone of efficient patient management. However diagnosis based on clinical evaluation alone has been accurate in only $65 \%$ of cases ${ }^{3}$. And is often associated with delay in diagnosis and treatment and unnecessary laparotomies are done due to considerable overlap of symptoms and signs of various disease entities causing acute abdomen ${ }^{4}$.

The purpose of laboratory tests and radiological examination is to confirm and/ or exclude diagnostic possibilities that are being considered based on a proper history and physical examination. The main goal of imaging in acute abdomen is to narrow down the differential diagnosis and for prompt treatment.

\section{Material and Methods}

The present study was cononducted in the Department of Radiodiagnosis, SMS Medical College \&Associate Group of Hospitals, Jaipur. All the patients with acute abdomen were included in the study. All the patient with acute abdomen come in Department of Radiodiagnosis with acute abdomen formed part of study. Patients with abdominal trauma, obstructed hernia and malignancy were excluded from the study. Patients were subjected to routine haematological, urine examination and biochemical estimations.

Results

Table 1: Role of USG in Acute Abdomen

\begin{tabular}{|l|l|l|l|l|}
\hline s.no. & Disease group & No. of X-ray & USG positive & Percentage \\
\hline $\mathbf{1}$ & Perforation Peritonitis & 50 & 47 & 94.00 \\
\hline $\mathbf{2}$ & Intestinal obstruction & 41 & 30 & 73.17 \\
\hline $\mathbf{3}$ & Appendicitis & 20 & 0 & 0 \\
\hline $\mathbf{4}$ & Appendicular lump & 20 & 12 & 60.00 \\
\hline $\mathbf{5}$ & APD & 20 & 0 & 0 \\
\hline $\mathbf{6}$ & Colitis & 18 & 0 & 0 \\
\hline $\mathbf{7}$ & Pancreatitis & 5 & 3 & 60 \\
\hline $\mathbf{8}$ & Renal stone & 20 & 20 & 100 \\
\hline $\mathbf{9}$ & Twisted ovarian cyst & 4 & 4 & 100 \\
\hline $\mathbf{1 0}$ & Abscess & 10 & 9 & 90 \\
\hline $\mathbf{1 1}$ & Total & 208 & 125 & 60.10 \\
\hline
\end{tabular}


USG was able to diagnose $94 \%$ cases of perforation peritonitis. Intestinal obstruction was diagnosed only in $73.17 \%$ of cases with USG.

\section{Discussion}

The acute abdomen remains a challenge to surgeons and other Physicians. Abdominal pain is most common cause for hospital admissions in most parts of the world. An early diagnosis of the underlying cause is of great value for prompt selection of appropriate management, surgical or conservative, thereby reducing the morbidity and mortality on one hand and unnecessary laparotomy on other.

Studies are available that have compare the role of USG and abdominal X-RAY in acute abdomen ${ }^{5,6}$.Walsh et $\mathrm{al}^{6}$, while evaluating the role of immediate USG in acute abdomen showed that USG was more informative than plain X-Ray in $40 \%$ of their cases. Simeone et al shown that while plain films scored over USG in 5\% cases only.

Overall plain film of abdomen was abnormal in 125 patients out of 208 USG carried out in 208 patients of acute abdomen.

\section{Conclusion}

This study shows that simple X-Ray plays an important role in definite diagnosis of acute abdomen as compare to USG.

\section{References}

1. Das S: Examination of an acute abdomen. A manual of clinical surgery Ch 2000; 33:335-356.

2. White $\mathrm{M}$ J and Counselman F.L.: Troubleshooting acute abdominal pain- Part 1 and 2. Emergency Medicine:Jan 2002.

3. Staniland JR, Ditchburn J et al: Clinical presentation of acute abdomen:study of 600 patients. BMJ 1972; 3:393- 398.

4. Schewerk WB, Wichtrup B, Rothmund M, Ruschoff $\mathrm{J}$ : Ultrasonography in diagnosis of acute appendicitis: a prospective study. Gastroenterology 1989; 97:60-639.

5. Simeone JF et al:Comparison of plain film and sonography in valuation of acute abdomen. AJR 1985; 144:49- 52.

6. Walsh PF, Crawford D, Crossling F T, Sutherland GR, Negrette JJ, Shand J: The value of immediate ultrasound in acute abdominal conditions. A critical appraisal. Clin. Radiol 1990; 42:47-49. 